Short Communication

\title{
Corrosion Resistance of Inconel 625 Overlay Welded Inside Pipes as a Function of Heat Treatment Temperature
}

\author{
So-dam Ban ${ }^{1}$, Young-Taek Shin ${ }^{2}$, Sung Riong Lee ${ }^{3}$, Hae-woo Lee $e^{1, *}$ \\ ${ }^{1}$ Department of Materials Science and Engineering, Dong-A University, Busan Rep. of Korea \\ ${ }^{2}$ Department of Naval Architecture and Offshore Engineering, Dong-A University, Busan, Rep. of \\ Korea. \\ ${ }^{3}$ Departmnet of Materials and Metallurgical Engineering, Kangwon National University, Kangwon-do, \\ Rep. of Korea. \\ *E-mail: hwlee@dau.ac.kr
}

doi: $10.20964 / 2016.09 .22$

Received: 1 June 2016 / Accepted: 12 July 2016 / Published: 7 August 2016

The effect of the heat treatment temperature on the corrosion resistance and precipitation of weld overlaid Inconel 625 has been investigated. Gas metal arc welding was performed using Inconel 625 as a filler metal with the ASTM A333Gr 6.The heat treatment was carried out on test specimens at $650^{\circ} \mathrm{C}$, $750{ }^{\circ} \mathrm{C}, 850^{\circ} \mathrm{C}$, and $950^{\circ} \mathrm{C}$ for 24 hours. After heat treatment, the microstructure and elemental composition was investigated. At $650^{\circ} \mathrm{C}$, the specimen showed a dendritic pattern, and secondary phases was observed, whereas the fine $\gamma^{\prime \prime}$-phase observed at $750^{\circ} \mathrm{C}$. At $850^{\circ} \mathrm{C}$, the $\delta$-phase was clearly observed, which was dissolved in the matrix at $950{ }^{\circ} \mathrm{C}$ and no longer visible. In addition, potentiodynamic polarization tests were performed to evaluate the pitting corrosion resistance. The results confirmed that there were no significant differences between the specimens. Double loop electrochemical potentiokinetic reactivationtests were undertaken to characterize the sensitization against intergranular corrosion. These results clearly showed that no sensitization occurred at any of the heat-treatment temperatures tested here.

Keywords: Inconel 625,Gas metal arc welding, overlay, potentiodynamic test, DL-EPR test

\section{FULL TEXT}

(C) 2016 The Authors. Published by ESG (www.electrochemsci.org). This article is an open access article distributed under the terms and conditions of the Creative Commons Attribution license (http://creativecommons.org/licenses/by/4.0/). 